\title{
Evaluation of drug prescriptions for pregnant women in the Legal Amazon Region
}

\author{
Vanessa Dela Justina 1 \\ Jéssica Silva Gonçalves 2 \\ Flávia Lúcia David 3 \\ Fernanda Regina Giachini 4 \\ Victor Vitorino Lima 5
}

1-5 Universidade Federal de Mato Grosso. Av. Valdon Varjão. Barra do Garças, MT, Brasil. CEP: 78.600-000. E-mail: vane_cessa@hotmail.com

\begin{abstract}
Objectives: to evaluate the drug prescriptions for pregnant women in the Legal Amazon during prenatal care.

Methods: this is a pharmacoepidemiological, descriptive, retrospective and crosssectional study. Medical records included sociodemographic variables, prenatal care, most frequent pharmacological classes prescribed, risk classification of drugs and possible drugdrug interactions among pregnant women.

Results: a total of 159 records from pregnant women, enrolled in the Unified Health System were used. Most pregnant women began prenatal consultations in the first trimester of pregnancy (53.3\%) whereas most of the drugs were prescribed in the second gestational trimester (55.5\%). The most used pharmacological classes, classified according to the National List of Essential Drugs were: antianemic preparations (52.9\%), vitamins (12.5\%) and analgesic (10.6\%). According to the risk classification, the highest prevalence of prescribed drugs belongs to category A (46.8\%), followed by category $C(28.9 \%)$, category $B$ (20.0\%) and category D (4.3\%). Eight possible drug-drug interactions were found, being considered with mild severity, and six classified with moderate risk.

Conclusions: the results demonstrate a lack of information regarding prescription drugs for pregnant women and this may endanger maternal and fetal health. It is essential that medical records be an effective therapeutic tool, which should be read, analyzed and reviewed in order to ensure effective and safe medical treatment.

Key words Drug interaction, Pregnancy, Prenatal care, Drug utilization, Risk classification
\end{abstract}




\section{Introduction}

The use of therapeutic drugs by pregnant women and their consequences to the fetus are issues of great concern, especially considering the thalidomide tragedy that occurred between the late 1950s and the early 1960 s. ${ }^{1}$ Even with advances in both research and technology, it is estimated that 5 to $10 \%$ of malformations are drug-induced ${ }^{2}$ and these malformations are among the top 10 causes of child mortality in the world. ${ }^{3}$

Both the National Agency of Sanitary Surveillance (ANVISA - Agência Nacional de Vigilancia Sanitária) in Brazil as well as the Food and Drug Administration (FDA) approve the news drugs registry only after evaluating results of the use of this drug in specfic populations. However, experiments to determine safety, efficacy and pharmacokinetic changes in pregnant women are rare because of the ethical impossibilities involved in the research of this public. 4,5

In general, data available regarding this public comes from the clinical observations of cases in which cause and effect factors are associated. For most drugs there is no prior scientific data on the true risk of its use during pregnancy.4-7 However, as in all populations, the pregnant woman is subject to health intercurrences that often require a drug therapy, in addition to the drug prescriptions inherent in the pregnancy process. This situation presents a great challenge for the professionals that attend this population, since it is necessary to correlate the physiological changes of pregnant women with the actions of the pharmacokinetics and the pharmacodynamics of these drugs.4,5 Epidemiological studies can be an important methodological tool to aid safe and effective drug therapy in pregnant women. Although useful, current classification systems do not guarantee complete safety, since the information contained is limited, and further studies are needed on the effects of drug use during pregnancy. 8,9

In order to inform the prescriber and the pregnant women, FDA classified the drugs into five categories of risk: category A, presenting no risk to the fetus; category B, animal studies did not result in risk to the fetus in the first trimester of pregnancy, but there are no controlled studies in pregnant women; category $\mathrm{C}$, research has shown adverse effects to the fetus of animals, however there are no controlled studies in pregnant women; category D, presents fetal risk, but for the benefit of the pregnant woman, the use is admitted; and category X, contraindicated in the gestational period. Such categories are also used by ANVISA. 9
Another relevant factor is associated with the concomitant use of two or more drugs, allowing the occurrence of drug-drug interaction. Regardless of the pharmacokinetic or pharmacodynamic mechanism, drug-drug interaction is one of the subjects most discussed in pharmacology for the clinical practice of health professionals. The concomitant use of several drugs as a strategy in drug therapy and the high access of these drugs in the market, amplifies the undesirable effects of the pharmacological therapy, being able to generate increase or reduction of the therapeutic and/or toxic effect of them.10,11 In this sense, the purpose of this study was to characterize the profile of pregnant women, as well as to evaluate the prescription of medications during prenatal care in relation to the following aspects: prenatal care, more prescribed pharmacological classes, drug risk ratings and possible drug-drug interactions in pregnant women, in a city in the Legal Amazon, in the State of Mato Grosso.

\section{Methods}

This is a descriptive, retrospective and crosssectional pharmacoepidemiological study, based on the analysis of medical records from the Basic Health Units (UBS - Unidades Básicas de Saúde) present in the city of Pontal do Araguaia, State of Mato Grosso. This city is in Legal Amazon at latitude 15o 50'43" south and longitude 520 00'33" west. It has an area of $2,738.63 \mathrm{~km}^{2}$ and an estimated population of 5,427 inhabitants. 12

The sample used was composed of all clinical records (159) from pregnant women, users of the Unified Health System (SUS - Sistema Único de Saúde), collected between 2013 and 2016. Data collection was performed in all UBS and health centers in Pontal do Araguaia: UBS Geraldo Pimenta de Almeida [National Registry of Health Facilities (CNES - Cadastro Nacional de Estabelecimentos de Saúde) - 2395622]; UBS Benjamin Correia de Miranda (CNES - 6152902) and municipal health center Luzia Nogueira de Moraes (CNES 2395614). All the units had a family health team composed of doctors, nurses, nursing technicians and community health agents. The following factors were investigated in the drug prescriptions:

- Classification of age groups was performed using the criteria established by the World Health Organization (WHO): adolescents (10 years to 19 years) and adults (20 to 59 years). The age of pregnant women ranged from 13 to 39 years;

-Socio-demographic data: age, schooling, marital status and consumption of alcohol and 
tobacco during pregnancy;

-Factors related to prenatal care (gestational period in which prenatal care began, medications prescribed by gestational trimester, and mean (total of all prescribed medications, divided by the total number of pregnant women in the study) number of medications prescribed by pregnant women;

-Most prescribed pharmacological classes during gestation, classified according to the Anatomical Therapeutical Chemical Classification System (ATC);

-Classification of drug risks used during pregnancy, as proposed by the FDA;

-Identification of possible drug-drug interactions in pregnant women. The interactions were described for potential adverse reactions and classified according to the interaction severity.

The inclusion parameter was based on the presence of at least two data from the patient profile, according to the medical records. From the 159 clinical records analyzed, 8 were excluded, totaling 151 medical records at the end of the analysis.

The data analysis was conducted using Epi Info version $7^{\circledR}$. Absolute frequency and percentage were calculated for the categorical variables, such as: schooling, marital status, occupation and smoking, among others. For continuous variables, such as age and prescribed drugs, the mean and standard deviation (SD) were used. The drug-drug interactions were identified through the Micromedex Healthcare Series database, which has information on approximately 8,000 drugs, and is able to analyze several types of drug-drug interactions simultaneously.

The requirements regarding the confidentiality and secrecy of the information were respected, in accordance with the determinations of Resolution 196/96, from the Ethics Committee of the National Health Council (CNS) and patients were not submitted to any type of intervention. The present study was approved by the Research Ethics Committee of the University Hospital Júlio Müller with case number: 987 / CEP-HUJM / 2011 and authorized by the Health Secretary of the target municipality.

\section{Results}

The characterization of the pregnant women attended by SUS in the municipality of Pontal do Araguaia is presented in Table 1. Approximately $77 \%$ of pregnant women were between 20 and 39 years old (mean age 23 years), of whom $35.8 \%$ were married or in a stable relationship. Regarding the occupation, $33.7 \%$ were unemployed, and most of the pregnant women attended the at least high school. Smoking (4.6\%) and the use of alcoholic beverages $(3.3 \%)$ during pregnancy were also reported (Table 1).

In the analysis regarding when the pregnant women started the prenatal follow-up, it was observed that 137 medical records $(90 \%)$ had this information. Of these, $53.3 \%$ of the clinical records demonstrated that pregnant women began prenatal consultations in the first trimester of pregnancy, $32.1 \%$ in the second trimester, and $5.1 \%$ in the third trimester. In relation to the quantity of drugs prescribed, according to the trimester of pregnancy (Table 1), it was observed that most drugs were prescribed in the second gestational trimester $(55.5 \%)$, followed by the first trimester $(27.7 \%)$ and third trimester $(16.8 \%)$. In this sample, the average number of drugs prescribed per pregnant woman was 2.4 medications.

According to the classification of ATC, Table 2 demonstrates the most prescribed pharmacological classes for pregnant women during pregnancy, as well as the drug most frequently found within each therapeutic class. Within the most prescribed classes were: antianemic preparations $(52.9 \%)$, vitamins $(12.5 \%)$, analgesics $(10.6 \%)$, antibiotics $(7.2 \%)$, antifungals and anti-acids (2.9\%), anti-inflammatories and antirheumatics $(2.4 \%)$ and corticosteroids $(1.9 \%)$.

Assessing the risk classification of drugs used during pregnancy (Table 3 ), according to FDA, the prevalence of higher consumption of drugs was, respectively, class A with folic acid (46.8\%); class C, with polyvinyl alcohol, polimineral, bisacodyl, among others $(28.9 \%)$; class B, with paracetamol, bromopride, among others (20\%); and class D, with ibuprofen $(4.3 \%)$. There were no drugs prescribed in class $\mathrm{X}$. In this study, eight possible drug-drug interactions were also found (Table 4), of which two were classified as mild and six were classified as moderate severity.

\section{Discussion}

Pregnant women are often exposed to drug use, and this at-risk population is often neglected by scientific studies related to the use of drugs.

Initially, the present study evidenced that pregnant women from this city located in the Legal Amazon presented a sociodemographic profile similar to other regions of Brazil, 13 in relation to the average age of the pregnant women, relationship profile and length of schooling. This similarity between studies may be related to the living condi- 
Table 1

Profile of pregnant women attended in the SUS of the municipality of Pontal do Araguaia - MT.

\begin{tabular}{|c|c|}
\hline Variable & \\
\hline Age group (years) $\quad \bar{X} \pm D P(\%)$ & \\
\hline $13-19$ & $16.9 \pm 1.5(23.2)$ \\
\hline $20-39$ & $26.1 \pm 5.1(76.8)$ \\
\hline \multicolumn{2}{|l|}{ Education $\quad n(\%)$} \\
\hline Elementary School & $50(33.1)$ \\
\hline High School & $76(50.3)$ \\
\hline College & $25(16.6)$ \\
\hline \multicolumn{2}{|l|}{ Marital status $\mathrm{n}(\%)$} \\
\hline Single & $38(25.2)$ \\
\hline Married/Relationship & $54(35.8)$ \\
\hline Do not declare/blank & $59(39.0)$ \\
\hline \multicolumn{2}{|l|}{ Ocupation n (\%) } \\
\hline Unemployed & $51(33.7)$ \\
\hline Employed & $29(19.2)$ \\
\hline Do not declare/blank & $71(47.1)$ \\
\hline \multicolumn{2}{|l|}{ Smoking in pregnancy $\mathrm{n}(\%)$} \\
\hline No & $144(95.4)$ \\
\hline Yes & $7(4.6)$ \\
\hline \multicolumn{2}{|l|}{ Alcoholic beverage in pregnancy $n(\%)$} \\
\hline No & $146(96.7)$ \\
\hline Yes & $5(3.3)$ \\
\hline \multicolumn{2}{|l|}{ Pre-natal onset $\mathrm{n}(\%)$} \\
\hline $1^{\text {st }}$ trimester & $73(53.3)$ \\
\hline 2nd trimester & $44(32.1)$ \\
\hline 3rd trimester & $7(5.1)$ \\
\hline Do not declare/blank & $13(9.5)$ \\
\hline \multicolumn{2}{|l|}{ Drugs prescribed per trimester $\mathrm{n}(\%)$} \\
\hline 1st trimester & $38(27.7)$ \\
\hline $2^{\text {nd }}$ trimester & $76(55.5)$ \\
\hline 3rd trimester & $23(16.8)$ \\
\hline Average number of medications per pregnant woman $(\bar{X} \pm D P)$ & $2.4 \pm 1.6$ \\
\hline
\end{tabular}

SUS= Sistema Único de Saúde (Unified Health System).

Table 2

Pharmacological groups and most prescribed drugs present in RENAME, according to the Anatomical Therapeutic Chemical Classification System - ATC, in the SUS of the municipality of Pontal do Araguaia - MT.

\begin{tabular}{lcc}
\hline Pharmacological class & N & $\%$ \\
\hline B03 - Antianemic preparations: & 110 & 52.9 \\
(B03BB01) Folic Acid & 65 & 59.1 \\
(B03AA07) Ferrous sulphate & 45 & 40.9 \\
A11-Vitamins: & 26 & 12.5 \\
(A11AA03) Polyvitamin and Poliminerals & 25 & 96.2 \\
(A11HA02) Pyridoxine hydrochloride & 1 & 3.8 \\
N02-Analgesics: & 22 & 10.6 \\
(N02BE01) Paracetamol & 16 & 72.7 \\
(N02BB02) Sodium dipyrone & 6 & 27.3
\end{tabular}

SUS= Sistema Único de Saúde (Unified Health System). 
Pharmacological groups and most prescribed drugs present in RENAME, according to the Anatomical Therapeutic Chemical Classification System - ATC, in the SUS of the municipality of Pontal do Araguaia - MT.

\begin{tabular}{|c|c|c|}
\hline Pharmacological class & $\mathbf{N}$ & $\%$ \\
\hline J01 - Antibacterials: & 15 & 7.2 \\
\hline (J01DB01) Cephalexin & 7 & 46.6 \\
\hline (J01CA04) Amoxicilin & 6 & 40.0 \\
\hline (J01XE01) Nitrofurantoin & 1 & 6.7 \\
\hline (J01DD04) Ceftriaxone & 1 & 6.7 \\
\hline D01 - Antifungals: & 11 & 5.3 \\
\hline (D01AC15) Fluconazole & 6 & 54.5 \\
\hline (D01AA01) Nystatin & 3 & 27.3 \\
\hline (D01AC08) Ketoconazole & 2 & 18.2 \\
\hline A02 - Antacids, medicines for peptic ulcer and flatulence: & 6 & 2.9 \\
\hline (A02AB01) Aluminum hydroxide & 3 & 50.0 \\
\hline (A02BA02) Ranitidine & 2 & 33.4 \\
\hline (A02BC01) Omeprazole & 1 & 16.6 \\
\hline M01 - Anti-inflammatory and Anti-rheumatic: & 5 & 2.4 \\
\hline (M01AE01) Ibuprofen & 5 & 100.0 \\
\hline H02 - Corticosteroids: & 4 & 1.9 \\
\hline (H02AB02) Dexametasone & 3 & 75.0 \\
\hline (H02AB09) Hydrocortisone & 1 & 25.0 \\
\hline Others & 9 & 4.3 \\
\hline
\end{tabular}

SUS= Sistema Único de Saúde (Unified Health System).

Table 3

General distribution of the drugs consumed by pregnant women attended at the UBSs of the city of Pontal do Araguaia (MT), according to the risk category for pregnant women proposed by the FDA.

\begin{tabular}{llll}
\hline Risk category & N & $\%$ & Main medications \\
\hline
\end{tabular}

A

46.8

Folic acid

B

47

20.0

Paracetamol, Bromopride, Chlorpheniramine, diclofenac sodium, scopolamine and pantoprazole.

C

68

28.9

Polyvitamin, poliminerals, bisacodyl,

carisprodol, magnesium hydroxide and hyoscyamine.

D

10

4.3

Ibuprofen

$\mathrm{X}$ 


\begin{tabular}{|c|c|c|}
\hline Drug interaction & Severity & Effect of concomitant use \\
\hline Furosemide vs Hydrocortisone & Moderate & Hypokalemia \\
\hline Ferrous Sulfate vs Ciprofloxacin & Moderate & Decreased efficacy of ciprofloxacin \\
\hline Omeprazole vs Carbamazepine & Moderate & Increased toxicity of carbamazepine \\
\hline Omeprazole vs Ferrous Sulfate & Moderate & Reduction of iron bioavailability \\
\hline $\begin{array}{l}\text { Aluminum Magnesium Hydroxide vs } \\
\text { Ferrous Sulphate }\end{array}$ & Minor & Decreased efficacy of iron \\
\hline Hyoscyamine vs Magnesium Hydroxide & Minor & Decreased efficacy of Hyoscyamine \\
\hline Ferrous Sulfate vs Pantoprazole & Moderate & Reduction of iron bioavailability \\
\hline Diclofenac Sodium vs Fluconazole & Moderate & Increased blood levels of diclofenac \\
\hline
\end{tabular}

SUS= Sistema Único de Saúde (Unified Health System).

tions in the evaluated municipality, defined for example by the Human Development Index (IDH), where Pontal do Araguaia display an IDH of 0.734 (2010), occupying the $920^{\text {th }}$ position, among the 5,565 Brazilian cities. 14

Habits such as alcohol and tobacco use during pregnancy are discouraged. The use of tobacco during pregnancy increases the risk of complications such as prepartum hemorrhage, preterm birth, miscarriage, low birth weight, sudden death of the newborn, among others. ${ }^{15}$ Cigarette smoking during pregnancy accounts for $20 \%$ of the cases of low birth weight fetuses, $8 \%$ of preterm births and $5 \%$ of all perinatal deaths. 16 The consumption of alcoholic beverages was confirmed in $3.3 \%$ of the analyzed pregnant women. A study performed with parturients from the extreme south of Brazil showed, through a pre-coded questionnaire, that $9.4 \%$ of pregnant women in the region used alcohol during pregnancy and that this use was related to low schooling, age and use of tobacco. ${ }^{13}$ Even with a low percentage of tobacco and alcohol use within the pregnant women evaluated in this study, it is important that a more enlightening and effective approach of health professionals can raise the awareness of pregnant women regarding the risks associated with the use of cigarettes and/or alcoholic beverages.

It is important to note that in this study, all the data were taken from the clinical records from pregnant women; consequently, the data related to the use of tobacco and alcohol were evaluated as a categorical variable and therefore in isolation, and these results present some limitations: in fact, the findings are not able to define aspects such as the frequency and type of beverage consumed. Therefore, any comparison between the data presented in this study and other studies related to tobacco and alcohol use should be made with caution.

It was observed that half of the pregnant women started their prenatal care in the first trimester. The delay in starting gestational care observed in pregnant women in the Legal Amazon region may favor greater risks to maternal and fetal health. Studies show that in other regions, such as Rio Grande do Sul, prenatal coverage in the first trimester reaches $80 \%$ of pregnant women. ${ }^{17}$ Women who started prenatal care in the first trimester, and consequently have a higher frequency of medical appointments, are more likely to follow medical guidelines and correctly use prescribed medications.

The use of at least one medication during gestation was observed in our study and is similar to other studies. 7,18 It is believed that this adherence to the use of medications derives, in part, from extensive prescription of vitamins, mineral supplements and antianemics, which are prescriptions inherent to the 
gestational process. 18 The present study demonstrates that the most prescribed pharmacological classes for pregnant women were antianemic $(52.9 \%)$ and vitamins $(12.5 \%)$, reflecting compliance with the Ministry of Health's guidelines for prenatal care.7,8,19 Similar values were found in studies conducted in developed countries such as France and Germany. 9,19

Anti-anemic preparations have been widely used by pregnant women, making it a routine procedure. Although it is a vitamin, folic acid belongs to the pharmacological class of antianemic preparations, since it acts correcting the resulting megaloblastic anemia. ${ }^{20}$ Maternal deficiency and/or use of medicinal products that antagonize metabolism in the periconceptional period are associated with an increased risk of neural tube abnormalities. ${ }^{1}$ The use of iron salts is also a routine intervention and is indicated to ensure adequate patterns of fetal development and maturation. A study carried out in six Brazilian cities highlighted the indiscriminate use of the anti-anemic class, since the evidence supporting this conduct is fragile and the benefits of treatment are not clearly defined.21 This assertion is supported by the fact that only 5 to $10 \%$ of iron ingested is absorbed under normal conditions, so daily intake through diet would be sufficient to maintain adequate levels. ${ }^{1}$ Although the need for this administration by healthy pregnant women is questioned, its use may be beneficial for populations with low nutritional status, where the prevalence of anemia and malnutrition is common. ${ }^{17}$ The high number of prescriptions of this mineral can be justified because the cost of diagnosis and follow-up of the table are higher than the costs of supplementing with iron salts. ${ }^{21}$ In addition, its use is advocated by the WHO due to the high rates of anemia in developing countries. 8

Pregnant women are also exposed to health intercurrences during pregnancy, often requiring the use of drugs that are foreign to the gestational process. Whatever the purpose of using a medication during pregnancy, it is always advisable to evaluate the benefit-risk for both mother and fetus. The effects of inadequate use of medications by pregnant women are often not noticed, since $15 \%$ of the malformations result in abortions at the beginning of the gestational period. Thus, attention is drawn to the importance of pharmacovigilance in detecting, evaluating, clarifying and preventing issues associated with drug insecurity during pregnancy. 22 Thus, the present study verified the classification of prescription drugs according to the risk during pregnancy and found that category A (46.8\%) was the most prescribed, followed by categories C (28.9\%), B (20\%) and D (4.3\%). Drugs belonging to classes B, C and D have their consumption associated with health intercurrences during pregnancy.9,23 Similar data were observed in a study conducted in southern Santa Catarina State. 22

Regarding the use of class B drugs $(20.0 \%)$, we can mention analgesics. Of this group, acetaminophen is the safest. Analgesics such as dipyrone and acetylsalicylic acid are classified in category $\mathrm{C}$ and represent a risk to the fetus. ${ }^{7}$ The former can cause agranulocytosis and the latter is associated with low birth weight, prolongation of gestation, and bleeding during delivery in mothers who used it at the end of pregnancy.7,8,23

The consumption of drugs of class $\mathrm{C}$ corresponded to $28.9 \%$ of the medicines used, totalizing the second higher frequency. Although risks are not excluded, their use can be justified by the fact that the benefits outweigh the potential risks. ${ }^{8}$ One example of this class is the use of antacids, such as magnesium hydroxide. High doses and chronicity of these medicines should be avoided due to the lack of adequate and controlled studies in humans. Adverse effects such as hypercalcemia, hypermagnesemia, hypomagnesemia, increased tendon reflexes, systemic alkalosis, edema, and weight gain due to sodium absorption were reported in laboratory animals that used it chronically. 24 However, there are also antacids classified in category $\mathrm{B}$ as pantoprazole.

Antispasmodic drugs are observed in both risk category B (scopolamine) and C (hyoscyamine). Scopolamine has not shown evidence of harmful effects during human pregnancy. In animals, it also did not present embryotoxic or teratogenic effects. Despite this, precautions should be taken, especially in the first trimester of gestation. ${ }^{25}$ Hyoscyamine usually occurs in combination with other active substances, such as dipyrone, which is contraindicated in pregnancy and therefore its use is not indicated. 26

The risk category D was characterized by the use of anti-inflammatories. These are commonly used by pregnant women for painful conditions including back pain, urinary tract infection, hemorrhoids, among others. Its use during the third trimester of gestation is contraindicated, since it has been associated with the possibility of fetal heart alterations, fetal pulmonary hypertension, low birth weight and coagulation changes. If treatment with this therapeutic class is necessary, preference should be given to prednisone in low doses.23,27

Of the drugs classified in categories B, C and D 
studied herein, antiemetic bromopride, antihistaminic chlorpheniramine, non-steroidal anti-inflammatory diclofenac sodium, antispasmodic scopolamine and hyoscyamine, antacids pontoprazole and magnesium hydroxide, bisacodyl laxative and carisprodol muscle relaxant are not listed in National List of Essential Medicines (RENAME - Relação Nacional de Medicamentos Essenciais). Approved by Ordinance No. 507/GM, RENAME includes products of proven safety, efficacy and therapeutic quality, being an essential instrument of action in SUS and basis for the organization of state and municipal lists. ${ }^{28}$ Even though it is not mandatory to join RENAME, it is recommended for SUS the use of these drugs. Despite this, it is common in this environment to observe the lack of priorities in the adoption of medicines by the medical professional, often caused by the irregularity in the supply of these. 29

The drug-drug interactions are able to result in problems of different severities, therefore the presence of these problems related to drugs is an important indicator of the quality of the prescription. 30 Among the charts, we observed eight possible drugdrug interactions, of which two are considered mild risk and six moderate risk, 11 which could affect the level of potassium, iron, as well as reduce the effect of medications such as ciprofloxacin or increase the toxicity of carbamazepine. The drug-drug interactions contained in the same prescription were considered, as well as the information available in the databases consulted. Among the drug interactions found in this study, it was observed that the medicines hyoscyamine, magnesium hydroxide, pantoprazole and diclofenac sodium are not included in the RENAME list. Therefore, a simple adaptation of the medical prescriptions to the recommendations of RENAME could minimize these risks.

The method used to analyze the interactions has limitations that must be considered when interpreting the data. It is not possible to establish causal relationships between the characteristics of the

\section{References}

1. Adam MP, Polifka JE, Friedman JM. Evolving knowledge of the teratogenicity of medications in human pregnancy. Am J Med Genet. 2011; 157: 175-82.

2. Olsen J. Some options in studying side effects of drugs taken during pregnancy. Eur J Epidemiol. 2015; 30 (11): 1137-9.

3. Dolk H, Loane M, Teljeur C, Densem J, Greenlees R, McCullough N, Morris J, Nelen V, Bianchi F, Kelly A Detection and investigation of temporal clusters of conge- patient, pharmacotherapy and the occurrence of drug interactions. The use of software detects potential drug interactions, which does not mean that the effects reported by concomitant use actually manifest themselves. ${ }^{31}$ Although data programs are important, they generally produce high prevalence of interactions. 32

It is also relevant to mention that this study, as well as several others that use medical records as a data collection instrument, 33 are subject to some limitations, such as the precariousness of information in the medical records. Often, medical records do not contain the information that is essential to patient care. In view of the above, it would be very important to elaborate measures aimed at improving the quality of the patient's medical records, since the poor quality of the medical records may reflect the quality of care provided to patients.

When it comes to analyzing medical records, the prescriptions of medications that are often unnecessary can be a reflection of the training of health professionals and the culture of valuing prescription drugs during a medical visit. The prescription is a sign of attention with the patient and the fact of not receiving a prescription of medicines can be interpreted by the patient as disinterest and even incompetence of the doctor and represent the rupture of the doctor-patient relationship.?

The data presented in this paper reveal that even after the thalidomide disaster, pregnant women continue to be exposed to many medicines whose safety is not always well established. Some phisicians continue to prescribe irrationally and excessively, exposing mother and fetus to serious risks. Other health professionals, due to the complexity of the topic, need to inform women of childbearing age about the risks and benefits of using medications in pregnancy and, through continuing education, to have knowledge of the profile of the medicines to orientate such information for the planning of interventions that raise awareness of the rational use of medication during pregnancy. nital anomaly in Europe: seven years of experience of the EUROCAT surveillance system. Eur J Epidemiol. 2015; 30: 1153-64.

4. Nordeng H, Ystrøm E, Einarson A. Perception of risk regarding the use of medications and other exposures during pregnancy. Eur J Clin Pharmacol. 2010; 66: 207-14.

5. Mitchell AA, Gilboa SM, Werler MM, Kelley KE, Louik C, Hernández-Díaz S. Medication Use During Pregnancy, With Particular Focus On Prescription Drugs: 1976-2008. 
Am J Obs Gynecol. 2011; 205 (1): 51.e1-51.e8.

6. Lupattelli A, Spigset O, Twigg MJ, Zagorodnikova K, Mårdby $\mathrm{AC}$, Moretti $\mathrm{ME}$, et al. Medication use in pregnancy: A cross-sectional, multinational web-based study. BMJ Open. 2014; 4 (2): 1-11

7. Kassada DS, Miasso AI, Angélica M, Waidman P, Silva S Prevalence and Factors Associated With Drug Use in Pregnant Women Assisted in Primary Care. Text Context Nurs. 2015; 24 (3): 713-21.

8. Brum LF da Si, Pereira P, Felicetti LL, Silveira RD. Utilização de medicamentos por gestantes usuárias do Sistema Único de Saúde no município de Santa Rosa (RS, Brasil). Ciênc Saúde Coletiva. 2011; 16 (5): 2435-42.

9. Briggs GG, Freeman RK, Yaffe SJ. Drugs in Pregnancy and Lactation 8th Edition: A Reference Guide to Fetal and Neonatal Risk. Obs Med. 2009; 2 (2): 89.

10. Ötles S, Senturk A. Food and drug interactions: a general review. Acta Sci Pol Technol Aliment. 2014; 13 (1): 89-102.

11. Le H, Je M. Potentially harmful drug-drug interactions in the elderly: a review. Am J Geriatr Pharmacother. 2011; 9 (6): $364-377$.

12. IBGE (Instituto Brasileiro de Geografia e Estatística). PAS - Pesquisa Anual de Serviços [Internet]. 2006 [Acesso em jun 2017]. Disponível em: http://cidades.ibge.gov.br/xtras/ perfil.php?codmun $=510665$

13. Meucci RD, Saavedra JS, Silva ES, Branco MA, Freitas JN, Santos M, et al. Consumo de bebida alcoólica durante a gestação entre parturientes do extremo sul do Brasil Rev Bras Saúde Matern Infant. 2017; 17 (4): 663-71.

14. PNUD FJP I. Pontal do Araguaia, MT [Internet]. Atlas do Desenvolv Hum no Brasil 2013 [Acesso em: 15 mai 2018]. p.1-11. Disponível em: http://www.atlasbrasil.org.br/2013/ pt/perfil_m/pontal-do-araguaia_mt

15. Ystrom E, Vollrath ME, Nordeng H. Effects of personality on use of medications, alcohol and cigarettes during pregnancy. Pharmacoepidemiol Prescr. 2012; 68: 845-51.

16. Bhandari NR, Day KD, Payakachat N, Franks AM, Mccain $\mathrm{K}$, Ragland D. Use and risk perception of electronic nicotine delivery systems and tobacco in pregnancy. Womens Health Issues. 2018; 28 (3): 251-7.

17. Brzezińska-Wcisło L, Zbiciak-Nylec M, Wcisło-Dziadecka D, Salwowska N. Pregnancy: a therapeutic dilemma. Postep Dermatol Alergol. 2017; 34 (5): 433-8.

18. Oliveira AD, Gama DP, Leopardi MG, Dias JMG, Lyra DP, Neves SJF. Aderência autorreferida a medicamentos prescritos durante a gestação. Rev Bras Ginecol Obs. 2012; 34 (4): 147-52.

19. Daw JR, Hanley GE, Greyson DL, Morgan SG. Prescription drug use during pregnancy in developed contries: a systematic review. Pharmacoepidemiol Drug Saf. 2011; 20 (9): 895-902.
20. Milman N, Paszkowski T, Cetin I, Castelo-Branco C. Supplementation during pregnancy: beliefs and Science. Gynecol Endocrinol. 2016; 32 (7): 509-16.

21. Mengue SS, Schenkel EP, Duncan BB, Schmidt MI. Uso de medicamentos por gestantes em seis cidades brasileiras. Rev Saúde Publica. 2001; 35 (5): 415-20.

22. Maia TL, Trevisol FS, Galato D. Uso de medicamentos no primeiro trimestre de gravidez: avaliação da segurança dos medicamentos e uso de ácido fólico e sulfato ferroso. Rev Bras Ginecol Obs. 2014; 36 (12): 541-7.

23. Araújo DD, Leal MM, Santos EJV, Leal LB. Consumption of medicines in high-risk pregnancy: Evaluation of determinants related to the use of prescription drugs and selfmedication. Brazilian J Pharm Sci. 2013; 49 (3): 491-9.

24. Gelusil: hidróxido de alumínio + hidróxido de magnésio + simeticona. Farm. Resp.: Florentino de Jesus Krencas. União Química Farmacêutica Nacional S/A. 2014. Bula de Remédio.

25. Buscopan: butilbrometo de escopolamina. Farm. Resp.: Dr. Ronoel Caza de Dio. EMS S/A. 2013. Bula de remédio.

26. Tropinal: bromidrato de hiosciamina + dipirona sódica + butilbrometo de escopolamina + metilbrometo de homatropina. Farm. Resp.: Maria Geisa P. de Lima e Silva. Germed Farmacêutica Ltda. 2014. Bula de Remédio.

27. Mulder B, Bijlsma MJ, Schuiling-Veninga CCM, Morssink LP, Puijenbroek E van, Aarnoudse JG, et al. Risks versus benefits of medication use during pregnancy: What do women perceive? Patient Prefer Adherence. 2017; 12 (20): $1-8$

28. Brasil. Ministério da Saúde. Relação Nacional de Medicamentos Essenciais: RENAME 2014. 9 ed. Brasília, DF; 2015.

29. Brasil. Ministério da Saúde. Política Nacional de Medicamentos. Brasília, DF; 2001.

30. Leão DFL, Moura CS, Medeiros DS. Avaliação de interações medicamentosas potenciais em prescrições da atenção primária de Vitória da Conquista (BA), Brasil. Ciênc Saúde Coletiva. 2014; 19 (1): 311-8.

31. Vieira LB, Max A, Reis M, Emanuela R, Lima F. Interações Medicamentosas Potenciais em Pacientes de Unidades de Terapia Intensiva. Rev Ciências Farm Básicas e Apl. 2012; 33 (3): 401-8.

32. Nightingale G, Pizzi LT, Barlow A, Barlow B, Jacisin T, McGuire M, Swartz K, Chapman A. The prevalence of major drug-drug interactions in older adults with cancer and the role of clinical decision support software. J Geriatr Oncol. 2018; 9 (5): 526-33.

33. Vasconcellos MM, Gribel EB, Moraes IHS de. Health records: evaluation of patient health charts in primary care, Rio de Janeiro, Brazil. Cad Saúde Publica. 2008; 24: 17382.

Received on September 19, de 2017

Final version presented on June 6, 2018

Approved on September 21, 2018 